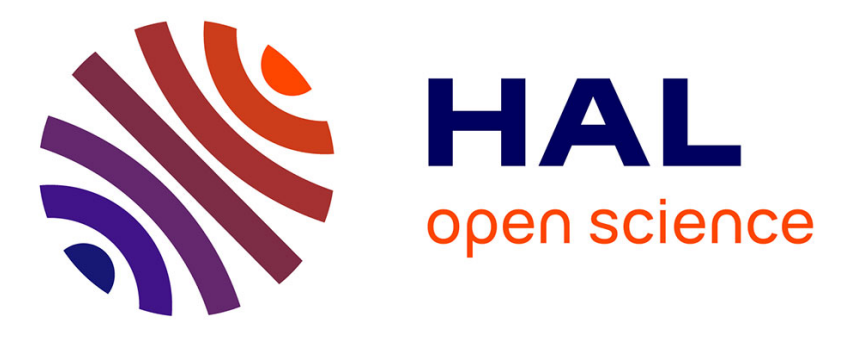

\title{
C_60 as an Atom Trap to Capture Co Adatoms
}

Peng Yang, Dongzhe Li, Vincent Repain, Cyril Chacon, Yann Girard, Sylvie

Rousset, Alexander Smogunov, Yannick J. Dappe, Cyrille Barreteau, Jérôme

Lagoute

\section{- To cite this version:}

Peng Yang, Dongzhe Li, Vincent Repain, Cyril Chacon, Yann Girard, et al.. C_60 as an Atom Trap to Capture Co Adatoms. Journal of Physical Chemistry C, 2015, 119, pp.6873-6879. 10.1021/jp512723c . cea-01366498

\section{HAL Id: cea-01366498 https: / hal-cea.archives-ouvertes.fr/cea-01366498}

Submitted on 14 Sep 2016

HAL is a multi-disciplinary open access archive for the deposit and dissemination of scientific research documents, whether they are published or not. The documents may come from teaching and research institutions in France or abroad, or from public or private research centers.
L'archive ouverte pluridisciplinaire $\mathbf{H A L}$, est destinée au dépôt et à la diffusion de documents scientifiques de niveau recherche, publiés ou non, émanant des établissements d'enseignement et de recherche français ou étrangers, des laboratoires publics ou privés. 


\title{
$\mathrm{C}_{60}$ as an Atom Trap to Capture Co Adatoms
}

\author{
Peng Yang, ${ }^{\dagger \neq}$ Dongzhe Li, ${ }^{\perp}$ Vincent Repain, ${ }^{\ddagger}$ Cyril Chacon, ${ }^{\ddagger}$ Yann Girard, ${ }^{\ddagger}$ Sylvie Rousset, ${ }^{\ddagger}$ \\ Alexander Smogunov, ${ }^{\perp}$ Yannick J. Dappe, ${ }^{\perp}$ Cyrille Barreteau, ${ }^{\perp, \S}$ and Jérôme Lagoute ${ }^{*, \neq}$ \\ ${ }^{\dagger}$ School of Advanced Materials and Nanotechnology, Xidian University, P.O. Box 207, 710071, Xi'an, China \\ ${ }^{\ddagger}$ Laboratoire Matériaux et Phénomènes Quantiques, UMR 7162, Université Paris Diderot et CNRS, Case courrier 7021, 75205 Paris \\ Cedex 13, France \\ ${ }^{\perp}$ Service de Physique de l'Etat Condensé (CNRS URA 2464), IRAMIS/SPEC, CEA Saclay, F-91191 Gif-sur-Yvette Cedex, France \\ ${ }^{\S}$ DTU NANOTECH, Technical University of Denmark, Ørsteds Plads 344, DK-2800 Kgs. Lyngby, Denmark
}

\section{Supporting Information}

ABSTRACT: $\mathrm{C}_{60}$ molecules were used to trap Co adatoms and clusters on a $\mathrm{Au}(111)$ surface using atomic/molecular manipulation with a scanning tunneling microscope. Two manipulation pathways (successive integration of single Co atoms in one molecule or direct integration of a Co cluster) were found to efficiently allow the formation of complexes mixing a $\mathrm{C}_{60}$ molecule with Co atoms. Scanning tunneling spectroscopy reveals the robustness of the $\pi$ states of $\mathrm{C}_{60}$ that
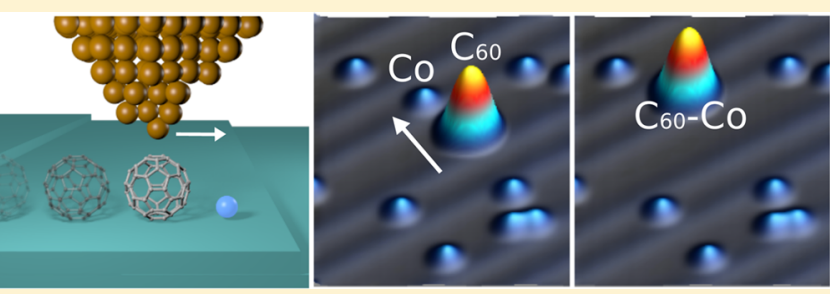
are preserved after Co trapping. Scanning tunneling microscopy images and density functional theory calculations reveal that dissociated Co clusters of up to nine atoms can be formed at the molecule-substrate interface. These results open new perspectives in the interactions between metal adatoms and molecules, for applications in metal-organic devices.

\section{INTRODUCTION}

Building artificial nanostructures by atomic/molecular manipulation with a scanning tunneling microscope (STM) offers the opportunity to unravel the physical phenomena that govern the matter at the nanometer scale. ${ }^{1-14}$ The rise of molecular electronics and spintronics has motivated a growing interest in molecule-metal interactions. STM experiments have been performed on individual manipulated molecule-metal conjugates ${ }^{5,6,13}$ providing a physical understanding of the interaction between molecules and metal atoms which is critical to build new generation molecular electronic devices and molecular machines. Being highly symmetrical, chemically reactive and produced easily in large amount, $\mathrm{C}_{60}$ is one of the most important members in the nanocarbon family ${ }^{15}$ and is a natural candidate for the study of model systems. The electronic spectrum and spatial mapping of molecular states of $\mathrm{C}_{60}$ adsorbed on different metallic substrates have been investigated by STM/STS ${ }^{16,17}$ and the interaction between a $\mathrm{C}_{60}$ molecule and $\mathrm{K}$ adatoms has been measured using lateral manipulation and revealed a charge transfer from $\mathrm{K}$ atoms to $\mathrm{C}_{60}{ }^{5}$. The interaction between $\mathrm{C}_{60}$ molecules and transition metals has also attracted many attentions. ${ }^{18-28}$ Significant magnetoresistance values have been reported for devices of $\mathrm{C}_{60^{-}}$ based spin valves with an electrode of cobalt. ${ }^{26,27}$ Furthermore, mixed thin films of $\mathrm{Co}$ and $\mathrm{C}_{60}$ exhibited large magnetoresistance. ${ }^{2,23}$ In such organometallic films, a charge transfer of 0.2 electrons/Co atom to the $\mathrm{C}_{60}$ molecule was measured, and a saturation composition was found for $\mathrm{Co}_{5} \mathrm{C}_{60}$ above which Co dense clusters are formed. ${ }^{29,30}$
In this work, using a low temperature STM, we manipulate atoms and molecules to build $\mathrm{C}_{60}-\mathrm{Co}_{x}$ complexes and study their electronic properties by scanning tunneling spectroscopy (STS). We reach an $x$ value of 9 , which is beyond the abovementioned saturation value of 5 in mixed films and is larger than previous manipulated metal-molecule complexes. We perform $\mathrm{dI} / \mathrm{dV}$ spectroscopy and conductance mapping to measure the electronic properties of the complexes. We find that although the interaction between $\mathrm{C}_{60}$ and $\mathrm{Co}$ is strong enough to obtain a $\mathrm{C}_{60}-\mathrm{Co}_{x}$ that can be moved on the surface as a single entity, the $\pi$ states of $\mathrm{C}_{60}$ are totally preserved; i.e., their energy position and wave function are not noticeably modified by the interaction with Co atoms and no evident charge transfer to these states is measured.

\section{EXPERIMENTAL METHOD}

The experiments were performed using a commercial Omicron low temperature STM operating under ultrahigh vacuum (UHV) $\left(<10^{-10} \mathrm{mbar}\right)$ and at low temperature $(5 \mathrm{~K})$. We used a chemically etched tungsten tip for the STM measurement. The differential conductance $(\mathrm{d} I / \mathrm{d} V)$ measurements were performed using the lock-in technique. The clean $\mathrm{Au}(111) /$ mica substrate was prepared by several cycles of $\mathrm{Ar}^{+}$ sputtering $(900 \mathrm{eV})$ followed by annealing at $600 \mathrm{~K}$ under UHV. The Co atoms were deposited by thermal evaporation of a $99.99 \%$ pure Co rod. $\mathrm{C}_{60}$ molecules were deposited from a

Received: December 20, 2014

Revised: March 3, 2015

Published: March 9, 2015 
$\mathrm{C}_{60}$ powder sublimated in a crucible heated at $600 \mathrm{~K}$. These depositions were made in situ on the $\mathrm{Au}(111) /$ mica surface maintained at low temperature $(5 \mathrm{~K})$. Atomic and molecular manipulation were performed using lateral manipulation with the STM tip. ${ }^{31}$ In a typical molecular manipulation process, at first the tip is moved around the molecule and the scanning is stopped. Then the tip height is modified in order to reduce the tip-sample distance with the goal to increase the tip-molecule interaction. Then the tip is moved laterally along a straight line to the final position while the molecule moves under the influence of the tip. Finally the tip is retracted vertically to the initial height and the scanning is restarted. The molecule is then left at the final position on the surface. The tunneling resistance is used to estimate the tip-molecule distance and interaction strength. The larger the tunneling resistance is, the stronger is the tip-molecule interaction. In our experiment, molecular manipulation could be achieved either in constant current or in constant height mode. In the constant current mode the feedback loop was active during the manipulation with a typical tunnel resistance of $5 \mathrm{M} \Omega$. In the constant height mode, the tip was first placed on top of the molecule (typical imaging parameter $1 \mathrm{~V}, 10 \mathrm{pA}$ ), then the feedback loop was turn off and the tip-sample distance reduced by about $5 \AA$ before performing the manipulation with the tip maintained at constant height.

\section{RESULTS AND DISCUSSION}

After depositon of $\mathrm{Co}$ and $\mathrm{C}_{60}$ on $\mathrm{Au}(111)$ at $5 \mathrm{~K}$, single molecules and adatoms are clearly observed on the surface as shown in Figure 1a. Using the STM tip we performed molecular manipulation and moved a $\mathrm{C}_{60}$ molecule toward a Co adatom, as shown in Figure 1a,b. In order to gain some insight into the cohesion of the $\mathrm{C}_{60}-\mathrm{Co}$ ensemble we performed an additional manipulation step (indicated by the arrow in Figure $1 b$ ) and moved the molecule away from the initial position of the Co adatom. After this manipulation, the Co adatom is no more observed on the surface, as shown in Figure 1c, indicating that it has been displaced together with the $\mathrm{C}_{60}$ and is now attached to the molecule. This moleculeatom ensemble will be called complex in the following. This $\mathrm{C}_{60}-\mathrm{Co}$ complex was in turn successively moved toward individual adatoms, as shown in Figure $1 \mathrm{~b}-\mathrm{f}$, in order to build $\mathrm{C}_{60}-\mathrm{Co}_{x}$ and explore the scalability of the process.

By this lateral manipulation $6 \mathrm{Co}$ atoms were taken by one $\mathrm{C}_{60}$ to build a $\mathrm{C}_{60}-\mathrm{Co}_{6}$ complex. Another way to build a $\mathrm{C}_{60}-$ $\mathrm{Co}_{x}$ complex is to move a molecule toward a $\mathrm{Co}_{x}$ cluster. To do this, we built a $\mathrm{Co}_{6}$ cluster by atomic manipulation and then moved a $\mathrm{C}_{60}$ molecule toward the cluster as shown in Figure 2a,b. Then we displaced away this molecule by an additional manipulation step from the initial position of the $\mathrm{Co}_{6}$ cluster (Figure 2b,c). After this manipulation, the $\mathrm{Co}_{6}$ cluster is no more observed on the surface suggesting that it is attached to the molecule and in turn formed $\mathrm{a}_{60}-\mathrm{Co}_{6}$ complex. In order to show the complex mobility and put more Co atoms into the complex, this $\mathrm{C}_{60}-\mathrm{Co}_{6}$ complex was moved successively by the STM tip toward the surrounding Co adatoms (Figure 2c). Finally, we have been able to add up to nine Co atoms to the $\mathrm{C}_{60}$ molecule (Figure $2 \mathrm{~d}$ ). It has to be noted that it was more difficult to move the complex on the surface when more Co atoms were contained in the complex.

The methods described above are both efficient to obtain the $\mathrm{C}_{60}-\mathrm{Co}_{x}$ complex although the building pathway is very different. The structure of these complex is therefore an open
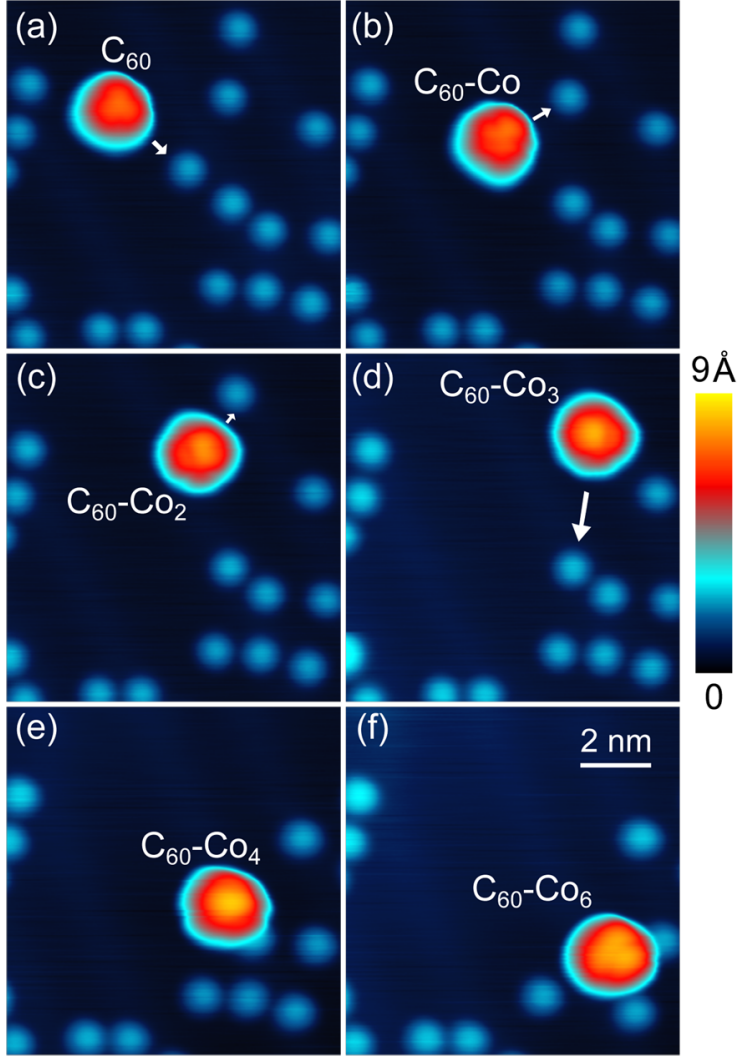

Figure 1. Series of STM images obtained during successive manipulations of $\mathrm{a}_{60}$ molecule toward Co adatoms that are taken one by one to build $\mathrm{C}_{60}-\mathrm{Co}_{x}$ complex. Note that the $\mathrm{C}_{60}-\mathrm{Co}_{4}$ complex has taken two nearby individual Co adatoms by one manipulation to form $\mathrm{C}_{60}-\mathrm{Co}_{6}$. To guide the eyes, the arrows indicate the moving direction of the molecule. All the STM images are taken with a bias voltage and current set point of $2 \mathrm{~V}$ and $20 \mathrm{pA}$, respectively.

question that we address in the following. We studied the apparent height of $\mathrm{C}_{60}$ and $\mathrm{C}_{60}-\mathrm{Co}_{x}$ measured from the topographic STM image. Various apparent heights have been measured for $\mathrm{C}_{60}$ organized on different metals. ${ }^{32-34}$ The apparent height of a $\mathrm{C}_{60}$ molecule measured by STM depends on the orientation of the molecule, the STM tip state, the adsorption site on the surface, and electronic differences caused by surface interaction. ${ }^{35,36}$ Therefore, the height of a molecule cannot be explained by a purely geometrical model as electronic effects must be taken into account. The electronic effects will be discussed below and we first address the expected geometric height. Because of its atomic structure, a fullerene $\mathrm{C}_{60}$ exhibits five typical orientations: (a) hexagone, (b) pentagone, (c) 6:6 bond, (d) 5:6 bond, and (e) apex atom, which correspond to the configurations of a hexagonal ring, a pentagonal ring, a bond joining two adjacent hexagonal rings, a bond joining a hexagonal and a pentagonal ring, and an apex atom riding on the surface, respectively. The geometric height (without considering the substrate) of pure $\mathrm{C}_{60}$ with different orientations is in the range of $6.48-7.05 \AA$ as given by an atomic model with a $\mathrm{C}-\mathrm{C}$ bond length of $1.43 \AA$. A van der Waals distance of about $2.5 \AA^{37}$ should be added to estimate the geometric height of an adsorbed molecule. Here, for a $\mathrm{C}_{60}$ molecule or $\mathrm{C}_{60}-\mathrm{Co}_{x}$ complex on $\mathrm{Au}(111)$ surface, the apparent height is measured as the vertical distance between the top of the molecule and the substrate along a scan line parallel to the reconstruction line (inset of Figure 3). As 

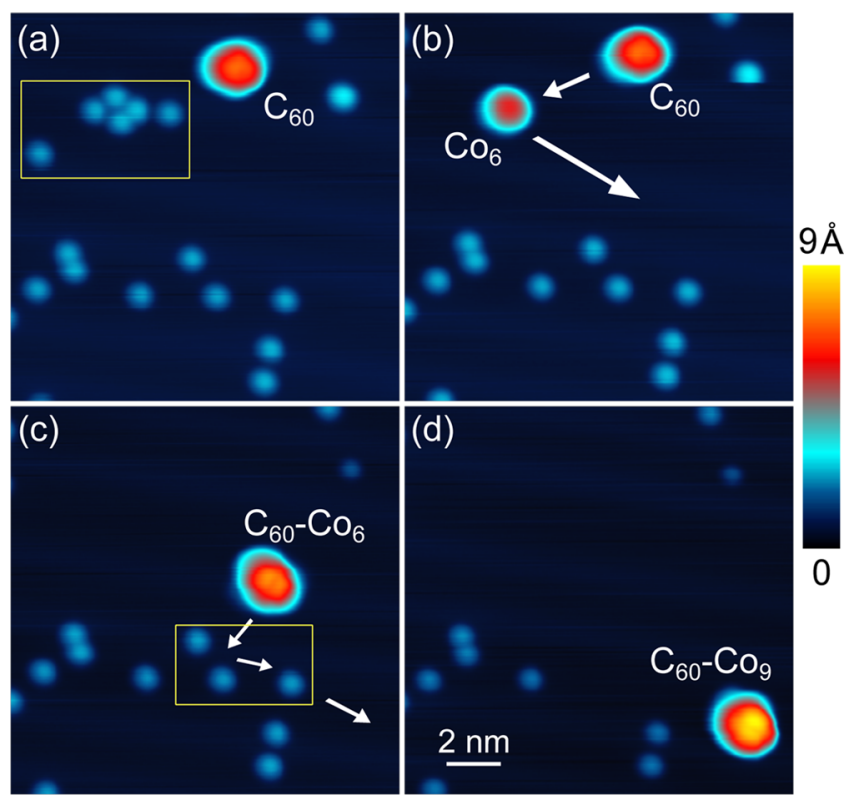

Figure 2. Series of STM images obtained during successive manipulations of a $\mathrm{C}_{60}$ molecule toward a Co cluster and Co adatoms. (a) A group of 6 Co adatoms (marked by a rectangle) is manipulated to form a $\mathrm{Co}_{6}$ cluster (b). (b to c) $\mathrm{A} \mathrm{C}_{60}$ molecule is moved onto this cluster to fabricate $\mathrm{C}_{60}-\mathrm{Co}_{6}$. Three neighbor $\mathrm{Co}$ adatoms are taken by $\mathrm{C}_{60}-\mathrm{Co}_{6}$ and finally a $\mathrm{C}_{60}-\mathrm{Co}_{9}$ complex is built (d). To guide the eyes, the arrows indicate the moving direction of the molecule. All the STM images are taken with a bias voltage and current set point of $2 \mathrm{~V}$ and $10 \mathrm{pA}$, respectively.

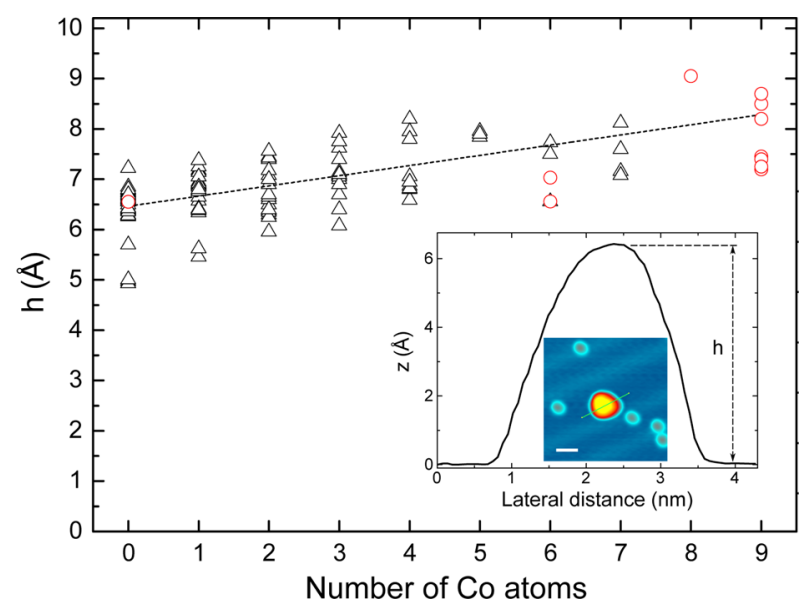

Figure 3. Apparent height $(h)$ of $\mathrm{C}_{60}$ and $\mathrm{C}_{60}-\mathrm{Co}_{x}$ measured by STM. The dotted line fits the average height at every $x$ value. The black triangle and red circle symbols correspond to one by one and cluster manipulation, respectively. Inset: the profile of a $\mathrm{C}_{60}$ molecule. All the apparent height measurements were carried out from STM images taken with a bias voltage of $2 \mathrm{~V}$.

illustrated in Figure 3, the apparent height of $\mathrm{C}_{60}$ is measured in the range of 4.9-7.3 $\AA$. This dispersion of the apparent height can be due to the molecular orientation, the adsorption sites or more complex effects. We measured that for a given orientation the height of $\mathrm{C}_{60}$ on a given adsorption site ( $f c c$ or $h c p$ ) can vary by about $1.6 \AA$. Therefore, the effect of orientation or adsorption site on the apparent height can not be clearly identified. However, the measured height is clearly smaller than the expected geometric height which may be due to electronic effects. It is clear that the $\mathrm{C}_{60}-\mathrm{Co}_{x}$ complexes also exhibit apparent height distributions. Despite this distribution, the average apparent height of $\mathrm{C}_{60}-\mathrm{Co}_{x}$ complex increases when the number of Co atoms increases from 0 to 9 as shown in Figure 3. This is also another evidence for the formation of the complex as the variation of the height reveals a difference between each structure. However, this increase does not correspond to the sum of $\mathrm{C}_{60}$ and Co clusters taken separately. For example, comparing the apparent height of $\mathrm{C}_{60}-\mathrm{Co}_{6}$ and pure $\mathrm{C}_{60}$, there is an increase of $\sim 2 \AA$, which is slightly larger than the height of a Co adatom $(\sim 1.6 \AA)$ and much smaller than the apparent height of $\mathrm{Co}_{6}$ cluster $(\sim 5.2 \AA)$. As will be discussed below, the electronic spectrum of the molecule is not strongly modified after the formation of a $\mathrm{C}_{60}-\mathrm{Co}_{x}$ complex, and therefore we expect that electronic effects will not play a major role in the height variations that are measured. It is worth to note that the complexes fabricated by either one-by-one (black triangle in Figure 3) or cluster (red circle in Figure 3) manipulation show the same trend in the apparent height. It suggests that the two methods, one-by-one and cluster manipulation, lead to complexes with the same structure. This can be understood as the typical time constant of the manipulation process (typically $1 \mathrm{~ms}$ between two successive tip displacements during manipulation) is much larger than the typical time constant of atomic relaxation, ${ }^{38}$ therefore the system can be considered as being in equilibrium during the process and independent of the pathway followed to build the complex.

In order to investigate the electronic interaction between $\mathrm{C}_{60}$ and Co atoms, we measured the influence of complex formation on the molecular orbitals of $\mathrm{C}_{60}$. We recorded $\mathrm{d} I$ / $\mathrm{d} V$ spectra with the STM tip located above the center of $\mathrm{C}_{60}$ molecules and different $\mathrm{C}_{60}-\mathrm{Co}_{x}$ complex obtained separately. As illustrated in Figure $4 \mathrm{a}$, three main resonance peaks, corresponding to the highest occupied molecular-orbital (HOMO), the lowest unoccupied molecular-orbital (LUMO), and LUMO+1 states, respectively, are observed in the differential spectrum of $\mathrm{C}_{60}$ molecules. Similar features are found for the $\mathrm{C}_{60}-\mathrm{Co}_{x}$ complex with slight shifts of peak position toward both high and low energies (Figure 4a). For the energy of the HOMO state, we determined the energy position after numerical derivation of the spectrum allowing us to measure the zero-slope point. Therefore, no charge transfer can be clearly evidenced between $\mathrm{Co}$ and $\mathrm{C}_{60}$. As illustrated by Xinhua et al., there is no obvious dependence of peak position on molecular orientation of $\mathrm{C}_{60}$ on $\mathrm{Au}(111) \cdot{ }^{17}$ The average energies of the HOMO, LUMO, and LUMO+1 states are around $-2.0,+1.1$, and $+2.4 \mathrm{eV}$ as shown in Figure $4 \mathrm{~b}$ for $\mathrm{C}_{60}$ molecule and $\mathrm{C}_{60}-\mathrm{Co}_{x}$ complex.

Simultaneously to the topographic STM image, we measured conductance maps on $\mathrm{C}_{60}$ molecule and $\mathrm{C}_{60}-\mathrm{Co}_{x}$ complex with different orientations. Such conductance maps allow to visualize the molecular orbitals at given bias voltage. As shown in Figure $\mathrm{S} 1$ in the Supporting Information, no clear difference is observed between the molecular orbitals of single $\mathrm{C}_{60}$ and those of complexes. This shows that although the interaction between $\mathrm{C}_{60}$ and $\mathrm{Co}$ is strong enough to capture single atoms or cluster, the influence of the hybridization between Co orbitals and $\mathrm{C}_{60}$ $\pi$ states is rather weak, so that the molecular orbitals remain unchanged. If the Co atoms were on the top of or beside the $\mathrm{C}_{60}$ molecule, a difference should be observed on the conductance map. Considering the fact that the difference between the apparent height of $\mathrm{C}_{60}-\mathrm{Co}_{6}$ and pure $\mathrm{C}_{60}$ is slightly larger than the apparent height of $\mathrm{Co}$ adatom and much 

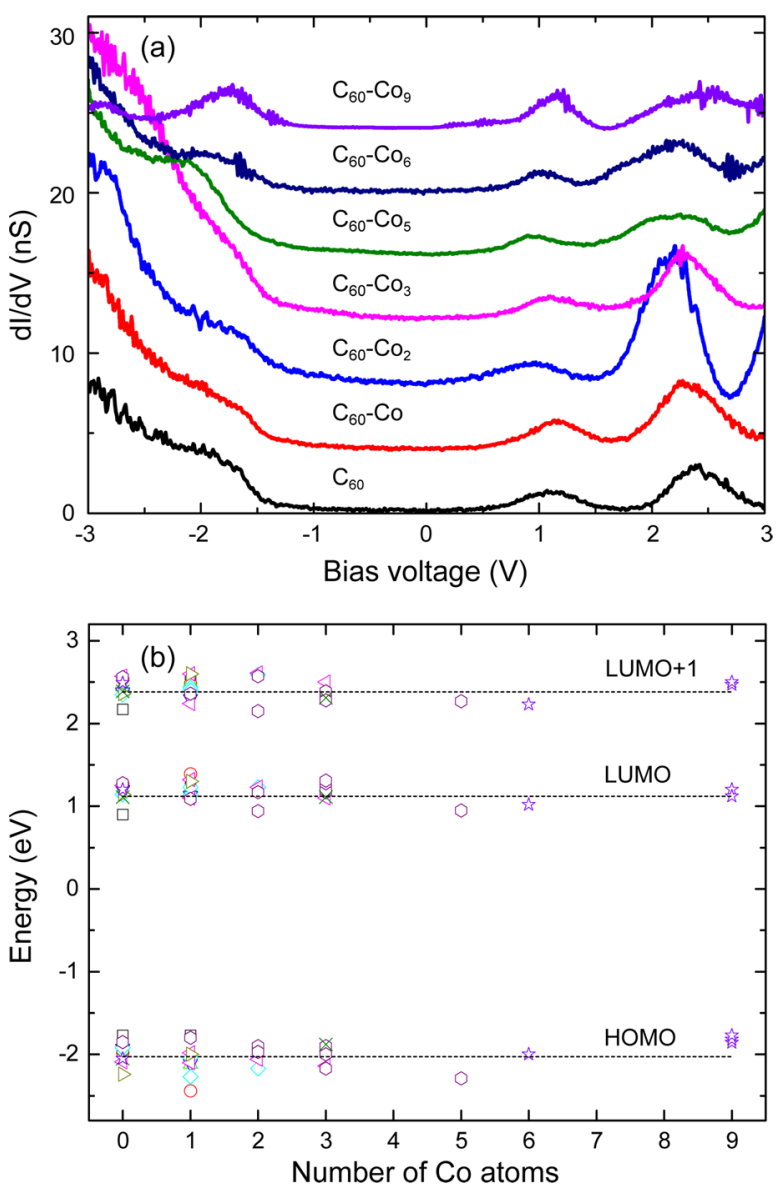

Figure 4. (a) Tunneling spectra for $\mathrm{C}_{60}$ and $\mathrm{C}_{60}-\mathrm{Co}_{x}$ showing three peaks around $-2.03,1.12$, and $2.38 \mathrm{~V}$ corresponding to the HOMO, LUMO, and LUMO+1 states, respectively. (b) Energies of HOMO, LUMO, and LUMO+1 for $\mathrm{C}_{60}$ and $\mathrm{C}_{60}-\mathrm{Co}_{x}$ measured by tunneling spectroscopy. The dotted lines correspond to the average energies of HOMO, LUMO, and LUMO+1 states for all the $x$ values. The colored symbols identify complex obtained with the same $\mathrm{C}_{60}$ molecule.

smaller than that of $\mathrm{Co}_{6}$ cluster, it is possible that the Co cluster dissociates when $\mathrm{C}_{60}-\mathrm{Co}_{x}$ complex is formed.

\section{FIRST-PRINCIPLES CALCULATIONS}

In order to interpret the experimental results, we performed DFT (density functional theory) calculations using a plane wave electronic structure package Quantum-ESPRESSO. ${ }^{39}$ Local density approximation in Perdew and Zunger parametrization ${ }^{40}$ was used for exchange-correlation functionals. The plane-wave cut-offs were set to 30 and $300 \mathrm{Ry}$ for the wave functions and for the charge density, respectively. A MarzariVanderbilt broadening scheme with a broadening width of 0.15 $\mathrm{eV}$ was used. The $\mathrm{Au}(111)$ substrate was simulated by a 5 layers $\mathrm{Au}$ slab with a bulk lattice parameter found to be $4.06 \AA$, close to experimental value of $4.08 \AA$. The first three Au layers were fixed while two other layers and $\mathrm{C}_{60}-\mathrm{Co}_{x}$ complex were relaxed until atomic forces become smaller than $0.001 \mathrm{eV} / \AA \AA$. A $(4 \times 4)$ in-plane periodicity was adopted for $\mathrm{Co} / \mathrm{Au}(111), \mathrm{C}_{60} /$ $\mathrm{Au}(111)$, and $\mathrm{C}_{60}-\mathrm{Co} / \mathrm{Au}(111)$ in order to avoid unphysical interactions between adsorbates and the $2 \mathrm{D}$ Brillouin Zone (BZ) was sampled with $(4 \times 4 \times 1) k$-points mesh. For a bigger $\mathrm{C}_{60}-\mathrm{Co}_{9} / \mathrm{Au}(111)$ complex, a bigger $(5 \times 5)$ in-plane supercell was employed.
To provide a simple energetic reasoning for a possibility to drag a single Co atom by a $\mathrm{C}_{60}$ molecule we present in Table 1

Table 1. Binding Energies, Atomic Bonds, and Spin Magnetic Moments for a Co Atom on $\mathrm{Au}(111)$ Surface (at Two Different Adsorption Sites: "fcc-hollow" and "bridge") and on Free $\mathrm{C}_{60}$ Molecule (above 6:6 Bond, the Lowest Energy Adsorption Site)

\begin{tabular}{lccc} 
& $\begin{array}{c}\mathrm{Co} / \mathrm{Au}(111) \mathrm{fcc}- \\
\text { hollow }\end{array}$ & $\begin{array}{c}\mathrm{Co} / \mathrm{Au}(111) \\
\text { bridge }\end{array}$ & $\begin{array}{c}\mathrm{C}_{60} / \mathrm{Co}, 6: 6 \\
\text { bond }\end{array}$ \\
$E^{b}(\mathrm{eV})$ & 4.10 & 3.97 & 2.69 \\
$d_{\mathrm{Co}-\mathrm{Au}}(\AA)$ & 2.42 & 2.37 & - \\
$d_{\mathrm{Co}-\mathrm{C}}(\AA)$ & - & - & 1.86 \\
$d_{\mathrm{C}-\mathrm{C}}(\AA)$ & - & - & 1.46 \\
$m_{\mathrm{S}}\left(\mu_{\mathrm{B}}\right)$ & 2.42 & 2.43 & 1.03 \\
\hline
\end{tabular}

binding energies of Co atom to free $\mathrm{C}_{60}$ molecule as well as to Au surface at two different adsorption sites: at "fcc-hollow" and "bridge". The difference between the two latters gives an estimate for the diffusion barrier of Co atoms along a $\mathrm{Au}$ surface, $E_{\text {diffusion }}=E_{\text {hollow }}^{b}-E_{\text {bridge, }}^{b}$, which was found to be $\approx 0.13$ $\mathrm{eV}$. Since the binding energy of $\mathrm{Co} / \mathrm{C}_{60}$ is much bigger than $E_{\text {diffusion }}$ but, from another side, is substantially smaller than the binding energy of $\mathrm{Co} / \mathrm{Au}(111)$, the $\mathrm{Co}$ atom will bind to $\mathrm{C}_{60}$ and slide with it along the $\mathrm{Au}$ surface, remaining, however, always in contact with the surface, exactly as it is found in experiment. Note that the spin magnetic moment for $\mathrm{Co} / \mathrm{C}_{60}$ was found to be $m_{S} \approx 1 \mu_{\mathrm{B}}$ which is twice smaller than that for $\mathrm{Co} / \mathrm{Au}(111), m_{S} \approx 2.4 \mu_{\mathrm{B}}$.

Next, we have studied the geometry and electronic structure of $\mathrm{C}_{60} / \mathrm{Au}(111), \mathrm{C}_{60}-\mathrm{Co} / \mathrm{Au}(111)$, and $\mathrm{C}_{60}-\mathrm{Co}_{9} / \mathrm{Au}(111)$ complexes (Figure 5). The lowest-energy configuration of $\mathrm{C}_{60} /$ $\mathrm{Au}(111)$ corresponds to a $\mathrm{C}_{60}$ hexagon placed right above an hcp-hollow site of a $\mathrm{Au}$ surface, in a good agreement with previous DFT calculations. ${ }^{41}$ In the case of $\mathrm{C}_{60}-\mathrm{Co} / \mathrm{Au}(111)$, the $\mathrm{Co}$ atom was found to bind at hollow site to a $\mathrm{Au}$ surface and at $6: 6$ bond to a $\mathrm{C}_{60}$ molecule, in agreement with our results for $\mathrm{Co} / \mathrm{Au}(111)$ and $\mathrm{Co} / \mathrm{C}_{60}$ presented above. The total spin moment of $\mathrm{C}_{60}-\mathrm{Co} / \mathrm{Au}(111)$ was found to be around $1.42 \mu_{\mathrm{B}}$. This value is much smaller than that for $\mathrm{Co} / \mathrm{Au}(111)$ $\left(2.42 \mu_{\mathrm{B}}\right)$ and reflects thus a general result of suppression of the Co magnetism due to binding to $\mathrm{C}_{60}$. For the $\mathrm{C}_{60}-\mathrm{Co}_{9} /$ $\mathrm{Au}(111)$ complex, we performed atomic relaxations with two different initial configurations: (i) Co atoms were distributed in some random fashion around $\mathrm{C}_{60}$ molecule (no any statistics was done since calculations are rather heavy); (ii) Co atoms form a compact $2 \mathrm{D}$ monolayer island on $\mathrm{Au}(111)$ with a $\mathrm{C}_{60}$ placed on top of it. We found that the first configuration is much more energetically favorable with respect to the second one, with an energy gain of about $0.97 \mathrm{eV}$. The Co atoms prefer thus to form a noncompact structure around $\mathrm{C}_{60}$, as shown on inset of Figure $5 \mathrm{c}$, which points to a strong tendency to dissociation of Co clusters due to the interaction with the $\mathrm{C}_{60}$ molecule. The total spin moment for this big complex was found to be around $13.71 \mu_{\mathrm{B}}$ which corresponds roughly to 1.52 $\mu_{\mathrm{B}}$ per Co atom.

We next check out the height change of $\mathrm{C}_{60}$ molecule due to the presence of $\mathrm{Co}$ adatoms on a $\mathrm{Au}$ surface, taking as a reference the topmost $\mathrm{C}_{60}$ atom of $\mathrm{C}_{60} / \mathrm{Au}(111)$. The measured heights were found to be increased by $\sim 0.14$ and $\sim 0.75 \AA$ for the $\mathrm{C}_{60}-\mathrm{Co} / \mathrm{Au}(111)$ and $\mathrm{C}_{60}-\mathrm{Co}_{9} / \mathrm{Au}(111)$ 


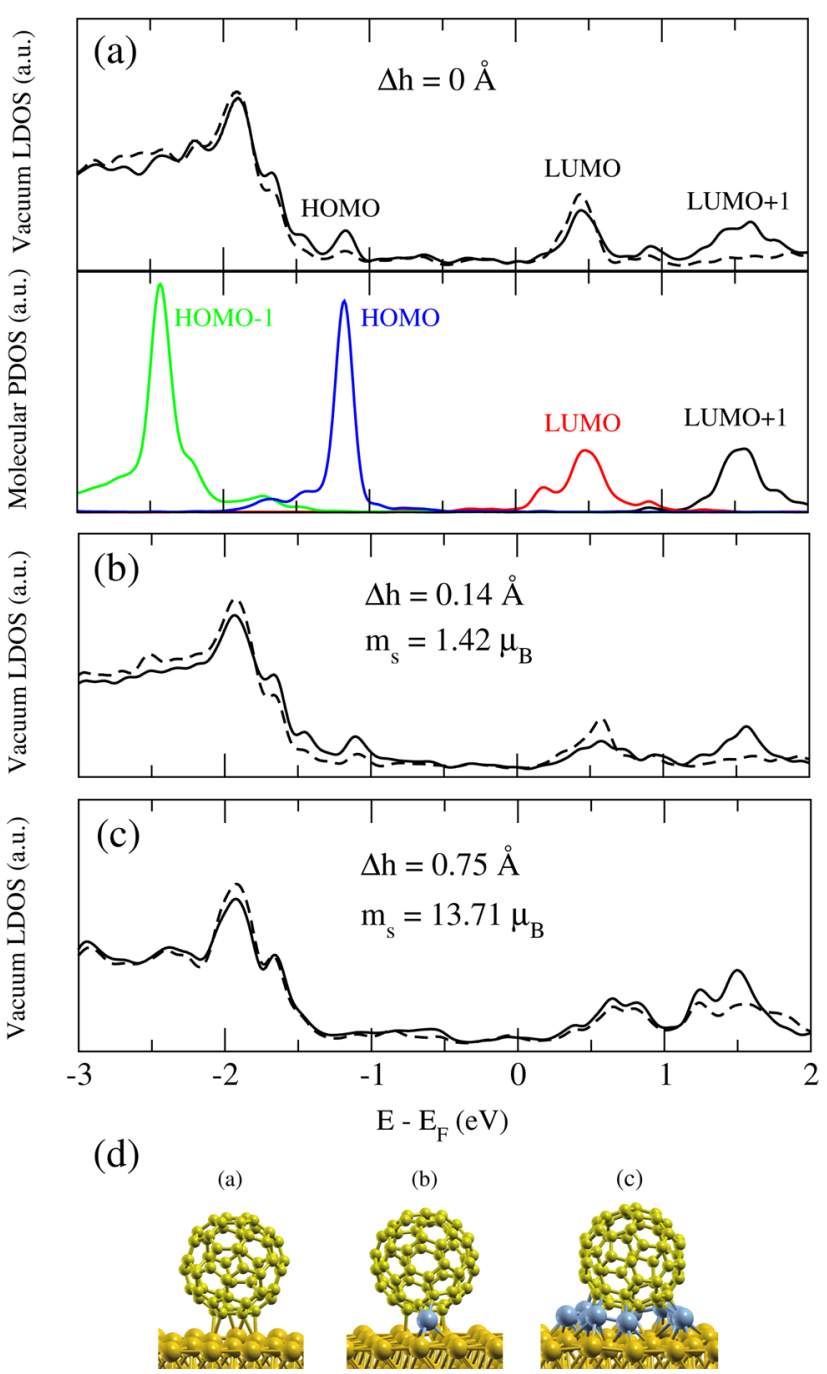

Figure 5. DFT calculations: vacuum LDOS at $6 \AA$ above the $\mathrm{C}_{60}$ for (a) $\mathrm{C}_{60} / \mathrm{Au}(111)$, (b) $\mathrm{C}_{60}-\mathrm{Co} / \mathrm{Au}(111)$, and (c) $\mathrm{C}_{60}-\mathrm{Co}_{9} / \mathrm{Au}(111)$ complexes, and $(\mathrm{d})$ the corresponding relaxed geometries. The LDOS for two different lateral positions are presented with solid and dashed lines. For the case of $\mathrm{C}_{60} / \mathrm{Au}(111)$ also the DOS projected onto molecular orbitals of the free $\mathrm{C}_{60}$ molecule is shown. The height change $\Delta h$ of $\mathrm{C}_{60}$ molecule (see text) and the total spin moments are also provided on each panel.

complexes, respectively, which is in a relatively good agreement with experimental data presented in Figure 3.

To simulate theoretically the STS spectra presented in Figure 4 we have used the well-known Tersoff-Hamman's expression for the tunneling differential conductance:

$$
G=\mathrm{d} I / \mathrm{d} V \propto n_{S}\left(R_{\mathrm{T}}, E_{\mathrm{F}}+e V\right)
$$

where $n_{S}\left(R_{\mathrm{T}}, E_{\mathrm{F}}+e V\right)$ is the total (spin up plus spin down) vacuum LDOS of the sample (the surface with adsorbate) calculated at the tip position $R_{\mathrm{T}}$ and at the energy corresponding to the applied voltage $V$. In practice, the vacuum LDOS is integrated over a small cubic box of the size which we choose here to be $0.4 \AA$. In Figure 5 such vacuum LDOS are presented for all three molecular complexes and for two different boxes (solid and dashed lines). These boxes are both placed at $6 \AA$ above $\mathrm{C}_{60}$ molecule but at slightly different lateral positions. One can see that the curves of LDOS correspond pretty well to the STS spectra shown in Figure 4. Their shape however depends somewhat on the lateral box position. In particular, LUMO+1 derived states (at $\sim 1.55 \mathrm{eV}$, see discussion below) are almost unvisible for the box represented by dashed lines.

In order to identify various features in vacuum LDOS, we also show in Figure $5 \mathrm{a}$ the DOS of $\mathrm{C}_{60} / \mathrm{Au}(111)$ projected onto different molecular orbitals of a free $\mathrm{C}_{60}$ molecule. This allows us to ascribe clearly the two LDOS peaks at $\sim 0.55 \mathrm{eV}$ and $\sim 1.55 \mathrm{eV}$ to LUMO and LUMO+1 derived states, respectively, and a small feature at $\sim-1.25 \mathrm{eV}$ (hardly visible for $\mathrm{C}_{60}-\mathrm{Co}_{9}$ / $\mathrm{Au}(111))$ to $\mathrm{HOMO}$ orbitals. Interestingly, a broad feature at $E$ $<-1.5 \mathrm{eV}$, seen in all LDOS curves, originates from the $\mathrm{Au}$ surface states, since, as we have checked, the similar structure was also observed for a clean $\mathrm{Au}(111)$ surface (without adsorbates). It should be noted however that the DFT is generally known to underestimate a LUMO-HOMO gap which was found here to be $\approx 1.8 \mathrm{eV}$ while the value of $\approx 2.6 \mathrm{eV}$ can be extracted from experimental STS spectra (see Figure 4). Overall, no significant change in vacuum LDOS curves was found among $\mathrm{C}_{60} / \mathrm{Au}(111), \mathrm{C}_{60}-\mathrm{Co} / \mathrm{Au}(111)$ and $\mathrm{C}_{60}-\mathrm{Co}_{9} /$ $\mathrm{Au}(111)$ complexes, which confirms the experimental results on STS spectra (Figure 4). Finally, we note that in Figure 5 the total LDOS, $n_{S}=n_{S}^{\uparrow}+n_{S}^{\downarrow}$, is presented which simulates the STS spectra taken with nonmagnetic STM tip. If the tip were spin-polarized it would select a preferable spin channel so that $n_{S}^{\uparrow, \downarrow}$ could be probed separately by changing the direction of the tip polarization. We did not find, however, significant spin polarization of vacuum LDOS (Figure S2 in the Supporting Information).

\section{CONCLUSIONS}

Through atomic and molecular manipulation of $\mathrm{C}_{60}$ molecules and $\mathrm{Co}$ adatoms on clean $\mathrm{Au}(111)$ surface at low temperature $(5 \mathrm{~K})$ using scanning tunneling microscopy, the $\mathrm{C}_{60}-\mathrm{Co}_{x}$ complex can be formed in two different ways: the molecule is successively moved toward individual adatoms, or a $\mathrm{Co}_{x}$ cluster is built by atomic manipulation then the molecule is moved toward the cluster. We have been able to add up to nine Co atoms to a $\mathrm{C}_{60}$ molecule, which is, to our knowledge, the largest number achieved in such molecule-metal atom complex. The $\mathrm{C}_{60}-\mathrm{Co}_{x}$ spectrum exhibit the main features of the $\mathrm{C}_{60}$ single molecule suggesting that the $\pi$ states are at most only slightly affected by the interaction between the molecule and the Co atoms. This is furtherly confirmed by the similarity between the conductance maps of $\mathrm{C}_{60}$ and $\mathrm{C}_{60}-\mathrm{Co}_{x}$. The conductance map and the apparent height measurement suggest that the Co cluster is dissociated between the $\mathrm{C}_{60}$ molecule and the $\mathrm{Au}$ (111) surface. These experimental results were explained and supported by DFT electronic structure simulations.

\section{ASSOCIATED CONTENT}

\section{S Supporting Information}

Conductance map, spin-polarized vacuum LDOS, and molecular dynamics simulations. This material is available free of charge via the Internet at http://pubs.acs.org.

\section{AUTHOR INFORMATION}

\section{Corresponding Author}

*(J.L.) E-mail: jerome.lagoute@univ-paris-diderot.fr.

\section{Notes}

The authors declare no competing financial interest. 


\section{ACKNOWLEDGMENTS}

The authors express thanks for the fruitful discussion with Dr. Xavier Bouju. The calculations in this work was performed using HPC resources from GENCI-CINES (Grant Nos. x2013096813).

\section{REFERENCES}

(1) Eigler, D. M.; Schweizer, E. K. Positioning Single Atoms with a Scanning Tunnelling Microscope. Nature 1990, 344, 524-526.

(2) Bartels, L.; Meyer, G.; Rieder, K. H. Basic Steps of Lateral Manipulation of Single Atoms and Diatomic Clusters with a Scanning Tunneling Microscope Tip. Phys. Rev. Lett. 1997, 79, 697-700.

(3) Heinrich, A. J.; Lutz, C. P.; Gupta, J. A.; Eigler, D. M. Molecule Cascades. Science 2002, 298, 1381-1387.

(4) Nazin, G. V.; Qiu, X. H.; Ho, W. Visualization and Spectroscopy of a Metal-Molecule-Metal Bridge. Science 2003, 302, 77-81.

(5) Yamachika, R.; Grobis, M.; Wachowiak, A.; Crommie, M. F. Controlled Atomic Doping of a Single $\mathrm{C}_{60}$ Molecule. Science 2004, 304, 281-284.

(6) Gross, L.; Rieder, K.-H.; Moresco, F.; Stojkovic, S. M.; Gourdon, A.; Joachim, C. Trapping and Moving Metal Atoms with a Six-Leg Molecule. Nat. Mater. 2005, 4, 892-895.

(7) Zhao, A.; Li, Q.; Chen, L.; Xiang, H.; Wang, W.; Pan, S.; Wang, B.; Xiao, X.; Yang, J.; Hou, J. G.; et al. Controlling the Kondo Effect of an Adsorbed Magnetic Ion through Its Chemical Bonding. Science 2005, 309, 1542-1544.

(8) Krull, C.; Robles, R.; Mugarza, A.; Gambardella, P. Site- and Orbital-Dependent Charge Donation and Spin Manipulation in Electron-Doped Metal Phthalocyanines. Nat. Mater. 2013, 12, 337343.

(9) Perera, E. U. G.; Ample, F.; Kersell, H.; Zhang, Y.; Vives, G.; Echeverria, J.; Grisolia, M.; Rapenne, G.; Joachim, C.; Hla, S. W. Controlled Clockwise and Anticlockwise Rotational Switching of a Molecular Motor. Nat. Nanotechnol. 2013, 8, 46-51.

(10) Dujardin, G.; Walkup, R. E.; Avouris, P. H. Dissociation of Individual Molecules with Electrons from the Tip of a Scanning Tunneling Microscope. Science 1992, 255, 1232-1235.

(11) Lee, H. J.; Ho, W. Single-Bond Formation and Characterization with a Scanning Tunneling Microscope. Science 1999, 286, 17191722 .

(12) Hla, S.-W.; Bartels, L.; Meyer, G.; Rieder, K.-H. Inducing All Steps of a Chemical Reaction with the Scanning Tunneling Microscope Tip: Towards Single Molecule Engineering. Phys. Rev. Lett. 2000, 85, 2777-2780.

(13) Repp, J.; Meyer, G.; Paavilainen, S.; Olsson, F. E.; Persson, M. Imaging Bond Formation between a Gold Atom and Pentacene on an Insulating Surface. Science 2006, 312, 1196-1199.

(14) Liljeroth, P.; Swart, I.; Paavilainen, S.; Repp, J.; Meyer, G. Single-Molecule Synthesis and Characterization of Metalligand Complexes by Low-Temperature STM. Nano Lett. 2010, 10, 24752479.

(15) Montellano Lopez, A.; Mateo-Alonso, A.; Prato, M. Materials Chemistry of Fullerene $\mathrm{C}_{60}$ Derivatives. J. Mater. Chem. 2011, 21, 1305-1318.

(16) Lu, X.; Grobis, M.; Khoo, K. H.; Louie, S. G.; Crommie, M. F. Spatially Mapping the Spectral Density of a Single $\mathrm{C}_{60}$ Molecule. Phys. Rev. Lett. 2003, 90, 096802-096802.

(17) Lu, X.; Grobis, M.; Khoo, K. H.; Louie, S. G.; Crommie, M. F. Charge Transfer and Screening in Individual $\mathrm{C}_{60}$ Molecules on Metal Substrates:A Scanning Tunneling Spectroscopy and Theoretical Study. Phys. Rev. B 2004, 70, 115418-115418.

(18) Balch, A. L.; Olmstead, M. M. Reactions of Transition Metal Complexes with Fullerenes $\left(\mathrm{C}_{60}, \mathrm{C}_{70}\right.$, etc. $)$ and Related Materials. Chem. Rev. 1998, 98, 2123-2166.

(19) Kurikawa, T.; Nagao, S.; Miyajima, K.; Nakajima, A.; Kaya, K. Formation of Cobalt- $\mathrm{C}_{60}$ Clusters: Tricapped $\mathrm{Co}\left(\mathrm{C}_{60}\right)_{3}$ Unit. J. Phys. Chem. A 1998, 102, 1743-1747.
(20) Nakajima, A.; Kaya, K. A Novel Network Structure of Organometallic Clusters in the Gas Phase. J. Phys. Chem. A 2000, 104, 176-191.

(21) Sakai, S.; Naramoto, H.; Avramov, P. V.; Yaita, T.; Lavrentiev, V.; Narumi, K.; Baba, Y.; Maeda, Y. Comparative Study of Structures and Electrical Properties in Cobalt-Fullerene Mixtures by Systematic Change of Cobalt Content. Thin Solid Films 2007, 515, 7758-7764.

(22) Sakai, S.; Mitani, S.; Sugai, I.; Takanashi, K.; Matsumoto, Y.; Entani, S.; Naramoto, H.; Avramov, P.; Maeda, Y. Effect of Cotunneling and Spin Polarization on the Large Tunneling Magnetoresistance Effect in Granular $\mathrm{C}_{60}-$ Co Films. Phys. Rev. B 2011, 83, $174422-174422$

(23) Miwa, S.; Shiraishi, M.; Tanabe, S.; Mizuguchi, M.; Shinjo, T.; Suzuki, Y. Tunnel Magnetoresistance of $\mathrm{C}_{60}-\mathrm{Co}$ Nanocomposites and Spin-Dependent Transport in Organic Semiconductors. Phys. Rev. B 2007, 76, 214414-214414.

(24) Sakai, S.; Sugai, I.; Mitani, S.; Takanashi, K.; Matsumoto, Y.; Naramoto, H.; Avramov, P. V.; Okayasu, S.; Maeda, Y. Giant Tunnel Magnetoresistance in Codeposited Fullerene-Cobalt Films in the Low Bias-Voltage Regime. Appl. Phys. Lett. 2007, 91, 242104-242104.

(25) Avramov, P.; Sakai, S.; Naramoto, H.; Narumi, K.; Matsumoto, Y.; Maeda, Y. Theoretical DFT Study of Atomic Structure and Spin States of the $\mathrm{Co}_{x}\left(\mathrm{C}_{60}\right)_{n}(x=3-8, n=1,2)$ Complex Nanoclusters. J. Phys. Chem. C 2008, 112, 13932-13936.

(26) Gobbi, M.; Golmar, F.; Llopis, R.; Casanova, F.; Hueso, L. E. Room-Temperature Spin Transport in $\mathrm{C}_{60}$-Based Spin Valves. Adv. Mater. 2011, 23, 1609-1613.

(27) Li, F. Effect of Substrate Temperature on the Spin Transport Properties in $\mathrm{C}_{60}$-Based Spin Valves. ACS Appl. Mater. Interfaces 2013, 5, 8099-8104.

(28) Cheng, P.-Y.; Chiang, M.-R.; Chan, Y.-L.; Hsu, Y.-J.; Wang, P.C.; Wei, D. H. Deep Co Penetration and Spin-Polarization of $\mathrm{C}_{60}$ Molecules at Hybridized Co- $\mathrm{C}_{60}$ Interfaces. Appl. Phys. Lett. 2014, 104, $043303-043303$.

(29) Sakai, S.; Naramoto, H.; Lavrentiev, V.; Narumi, K.; Maekawa, M.; Kawasuso, A.; Yaita, T.; Baba, Y. Polymeric Co- $\mathrm{C}_{60}$ Compound Phase Evolved in Atomistically Mixed Thin Films. Mater. Trans. 2005, $46,765-768$.

(30) Lavrentiev, V.; Abe, H.; Naramoto, H.; Sakai, S.; Narumi, K. Polymeric Chains in $\mathrm{C}_{60}$ and Co Mixture. Chem. Phys. Lett. 2006, 424, 101-104.

(31) Hla, S.-W. Scanning Tunneling Microscopy Single Atom/ Molecule Manipulation and Its Application to Nanoscience and Technology. J. Vac. Sci. Technol., B 2005, 23, 1351-1360.

(32) Grobis, M.; Lu, X.; Crommie, M. F. Local Electronic Properties of a Molecular Monolayer: $\mathrm{C}_{60}$ on $\mathrm{Ag}(001)$. Phys. Rev. B 2002, 66, $161408-161408$

(33) Altman, E. I.; Colton, R. J. Nucleation, Growth, and Structure of Fullerene Films on $\mathrm{Au}(111)$. Surf. Sci. 1992, 279, 49-67.

(34) Giudice, E.; Magnano, E.; Rusponi, S.; Boragno, C.; Valbusa, U. Morphology of $\mathrm{C}_{60}$ Thin Films Grown on $\mathrm{Ag}(001)$. Surf. Sci. 1998, 405, L561-L565.

(35) Altman, E. I.; Colton, R. J. The Interaction of $\mathrm{C}_{60}$ with Noble Metal Surfaces. Surf. Sci. 1993, 295, 13-33.

(36) Fasel, R.; Aebi, P.; Agostino, R. G.; Naumovi, D.; Osterwalder, J.; Santaniello, A.; Schlapbach, L. Orientation of Adsorbed $\mathrm{C}_{60}$ Molecules Determined via X-Ray Photoelectron Diffraction. Phys. Rev. Lett. 1996, 76, 4733-4736.

(37) Hamada, I.; Tsukada, M. Adsorption of $\mathrm{C}_{60}$ on $\mathrm{Au}(111)$ Revisited: A Van Der Waals Density Functional Study. Phys. Rev. B 2011, 83, 245437-245437.

(38) Bouju, X.; Joachim, C.; Girard, C. Single-Atom Motion During a Lateral STM Manipulation. Phys. Rev. B 1999, 59, R7845-R7848.

(39) Giannozzi, P.; Baroni, S.; Bonini, N.; Calandra, M.; Car, R.; Cavazzoni, C.; Ceresoli, D.; Chiarotti, G. L.; Cococcioni, M.; Dabo, I.; et al. Quantum Espresso: A Modular and Open-Source Software Project for Quantum Simulations of Materials. J. Phys.: Condens. Matter 2009, 21, 395502-395502. 
(40) Perdew, J. P.; Zunger, A. Self-Interaction Correction to DensityFunctional Approximations for Many-Electron Systems. Phys. Rev. B 1981, 23, 5048-5048.

(41) Wang, L.-L.; Cheng, H.-P. Density Functional Study of the Adsorption of a $\mathrm{C}_{60}$ Monolayer on $\mathrm{Ag}(111)$ and $\mathrm{Au}(111)$ Surfaces. Phys. Rev. B 2004, 69, 165417-165417. 